International Journal of Trend in Scientific Research and Development (IJTSRD)

Volume: 3 | Issue: 4 | May-Jun 2019 Available Online: www.ijtsrd.com e-ISSN: 2456 - 6470

\title{
Child Malnourishment in India \& its Scientific Solutions
}

\author{
Misbah Khan \\ Student, MS Ramaiah University of Applied Sciences, Gnanagangothri Campus, Bangalore, Karnataka, India
}

\begin{abstract}
How to cite this paper: Misbah Khan "Child Malnourishment in India \& its Scientific Solutions" Published in International Journal of Trend in Scientific Research and Development (ijtsrd), ISSN: 24566470, Volume-3 | Issue-4, June 2019, pp.556-558, URL: https://www.ijtsrd.c om/papers/ijtsrd23 836.pdf

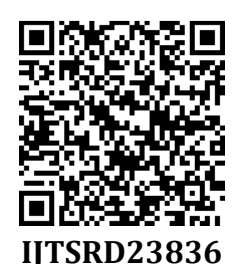

Copyright (C) 2019 by author(s) and International Journal of Trend in Scientific Research and Development Journal. This is an Open Access article distributed under the terms of the Creative Commons

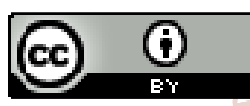
Attribution License (CC BY 4.0) (http://creativecommons.org/licenses/ by $/ 4.0$ )

\section{INTRODUCTION}

Malnutrition refers to undernutrition resulting from inadequate consumption, poor absorption, and excessive loss of nutrients and even lack of sanitation. It can also encompass overnutrition, resulting from overeating or excessive intake of specific nutrients due to improper diet, often observed in economically developed countries e.g. as indicated by increasing levels of obesity. It may range from mild to severe and even life threatening. It thereby remains a significant global problem, especially in developing and underdeveloped countries like India where more than 100 districts in the country, make India home to the largest number of malnourished children.

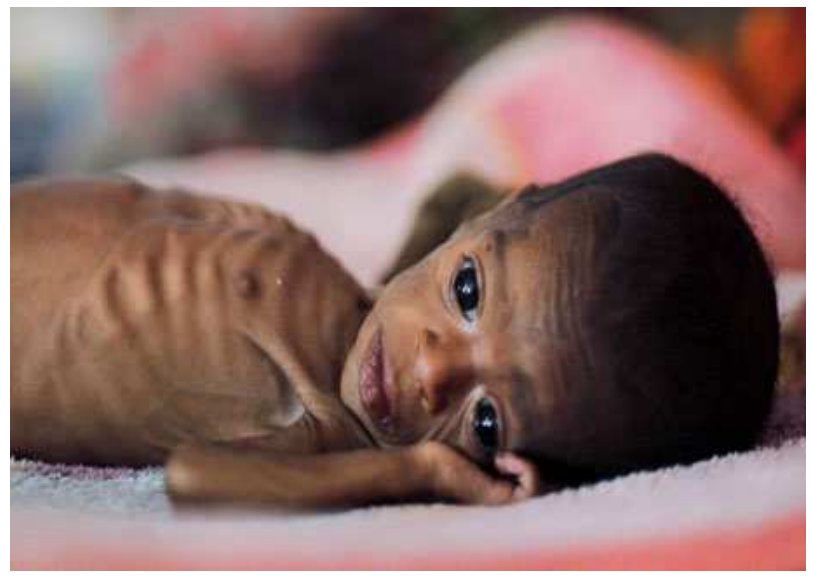

Fig1. 30 months old child weighing just $6.5 \mathrm{~kg}$ in MP (Source; Down to earth org)

\section{Explication:}

It's high time to focus on production diversity as well as food fortification at a macro level. Taking into consideration, millets that are 4-5 times more nutritious than rice and wheat in terms of proteins minerals and vitamins. They are cost effective crops as well, yet considered poor people's crops while rice and wheat are preferred over them. Millets being rich in calcium, iron, potassium, magnesium and zinc are gluten free, even suitable for people with gluten allergies and those with high blood glucose levels. As the dominant food choices lack in iron content, rates of anaemia among women in India, about $48 \%$ are some of the worst in the world, ranking at 170 out of 185 nations. As millets is a nutritious grain with qualities that make it superior to rice and wheat, it must be a much needed nutrition intervention tool, especially in rural India where Government should take the initiative to provide it at a much cheaper rate especially to those having BPL ration cards and should also be included in PDS distribution.

Besides, crops can be bio fortified through selective breeding or genetic engineering. In India, bio fortification is done exclusively through selective breeding. Though bio fortified foods are not available off the shelf just yet, its really the next big thing in nutrition to look out for and if evenly distributed can be a major step towards eradicating malnourishment from our country.

Taking into consideration the poverty and illiteracy rate of our country, home based management of SAM (severe acute malnutrition) with a locally produced ready to use 
therapeutic food (RUTF) is feasible, acceptable, affordable and very cost effective in terms of the disability adjusted life years saved and gross national income per capita of the country. The treatment of SAM at home needs serious attention and integration into the existing health system, along with actions to prevent SAM [4]. According to a study which was conducted in Delhi, Udaipur and Vellore as a randomised trial to compare the efficacy of a centrally produced RUTF (RUTF-C) and locally prepared RUTF (RUTFL) for home-based management of children with uncomplicated SAM on recovery rates compared with micronutrient enriched (augmented), energy-dense, homeprepared food (A-HPF) RUTF-L was found more efficacious than A-HPF at home. The recovery rates with RUTF-L, RUTFC and A-HPF were $56.9 \%, 47.5 \%$ and $42.8 \%$, respectively. This is the first randomised trial confirming that RUTF-L is more efficacious than A-HPF at home [5].

Efforts can be made by the Nutritionists and Biotechnologists to enhance the quality and nutritional value of RUTF and to keep it cost effective at the same time to avoid any reluctant response from the people.

Besides, Government of India has also taken several initiatives for instance;

1. Integrated Child Development Services (ICDS) Program

2. Mothers Absolute Affection (MAA)

3. National Iodine Deficiency Disorders Control Program (NIDDCP)

4. National Nutritional Anaemia Prophylaxis Program (NNAPP)

5. Rajiv Gandhi Scheme for Empowerment of Adolescent Girls (RGSEAG) - 'SABLA'

6. Nutri Farms Scheme

7. Weekly Iron and Folic Acid Supplementation (WIFS) Program

8. Tamil Nadu Mid-Day Meal Scheme /Nutritious Meal Program (NMP)

9. Kishori Shakti Yojana' (KSY)

10. National Food Security Mission (NFSM)

Although these yojanas have already been implemented and have benefitted a lot of people but there are still many unreached and hence many other alternative ways to overcome such problems.

The use of child growth monitor for instance is an innovative idea for reliable monitoring and data processing for malnourished children under five years. It is based on a mobile application using augmented reality in combination with artificial intelligence. By determining weight and height through 3D scan of children, the application can instantly detect malnutrition and if stressed more on, can provide a way to access easily to the people and treat children without even visiting doctors.

It can be both effective and cost efficient.

Even the AgriSafe $^{\mathrm{TM}}$ network, a non-profit national membership organization, represents health professionals and educators who are concerned about the health and safety of farm families and play a major role in eradicating malnourishment and poverty from our country, especially amongst the farmers who suffer in the hands of profit makers. Contributions can be made from the scientists and other organizations to introduce more techniques into this and make it reachable to one and all.

Additionally, Islam's holistic approach to health includes treating our bodies with respect and nourishing them with, not only faith, but also with lawful, nutritious food. A major part of living life according to the Creator's instructions is implementing a suitable diet. Choosing wholesome food and avoiding the unwholesome is essential to good health. God says in the Quran, "Eat of the good things which we have provided for you." (Quran 2:172) The idea is that religious leaders or other opinion leaders in the community become actively involved in designing material for education and providing advice. Like the Government of Afghanistan has initiated the concept of Quran for nutrition. It aims to improve the nutrition of pregnant and breastfeeding women and children. The main element of the idea is to take notice of local traditions and to cooperate with local opinion leaders instead of appearing to be an unwanted competition. If proper education is given to the people especially in rural areas and they are made aware of the significance of balanced diet in our lives and also how healthy eating is related to the interconnectedness of physical and spiritual health, it will undoubtedly play a major role towards creating a healthy nation. [6]

Besides, digital health shall also be prioritized and more technologists and scientists must work on making it a success, as better health moves humanity forward.

Implementation of ideas and looking forward to the development of our country is of no use without reaching out to the people and making them aware of the current scenarios and health issues taking place due to lack of sanitation which again contributes immensely towards the high malnourishment rate in India.

India is the capital of open defecation; approximately $59 \%$ of the people defecate in open places. The 2011 census showed that $46.9 \%$ household has toilets and $3.2 \%$ use public toilets; remaining $49.8 \%$ of people are defecating in the open. The practice has been widely accepted for generations, becoming a well-established tradition deeply ingrained from early childhood and is almost an accepted part of the Indian landscape. Open defecation is rampant in rural India where it is practiced by nearly $70 \%$ of the rural population, compared to $13 \%$ in urban areas. [7]

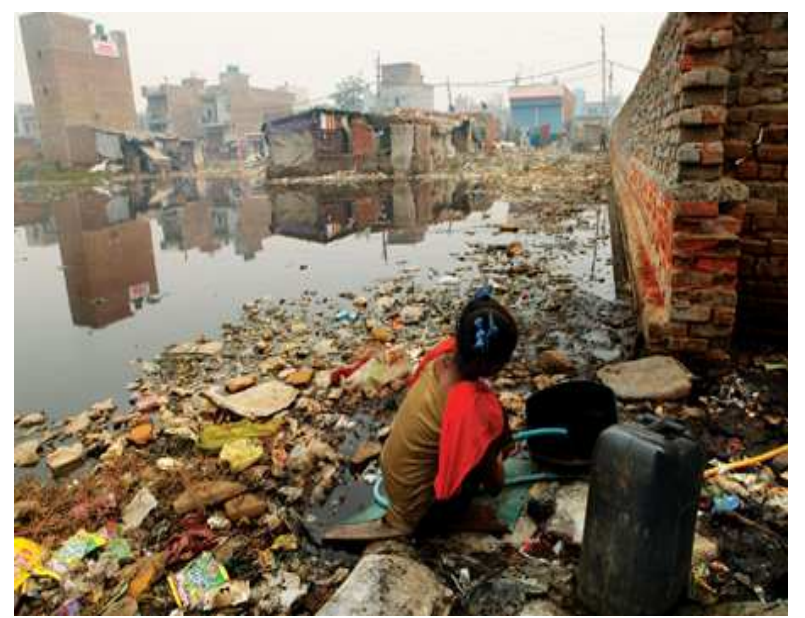

Fig 1.2 People defecating in open (Source; Down to earth org) 
Due to open defecation, lack of sanitation and hygiene is the major factor in causing various diseases, particularly; diarrhoea and intestinal worm infections, typhoid, cholera, hepatitis, polio, trachoma and others.

There can be many reasons why a person openly defecates and these may include; poor sanitation, lack of awareness, non availability of toilets, public toilets are available but are grimy, dark, smell bad or unattractive due to non maintenance, public toilets ain't available as part of the household but only at some distance and it may be dangerous to get there at night.

Therefore the reasons for open defecation are varied and it can undeniably be a voluntary Choice but in most cases it is due to the fact that the alternatives (i.e. Public toilets) are available yet not attractive. Open defecation is an extremely complex issue and it needs a holistic approach. Now Swachh Bharat Abhyan (SBA) mission is bringing partial change but, we need complete change to achieve open defecation free country through effective implementation of proper schemes and bringing out alternatives that'll be readily accepted by even the backward tribes of our country.

From scientific approach, making people aware of the consequences of continuing the unhygienic practices through papers, articles and campaigns and providing them with sanitizers and chemical sterilizers for better living will bring a huge change. Also usage of sewage treatment plants and bioremediation must be given priority for proper removal of wastes over incineration that can be a cause of pollution or disposal of wastes into water bodies that again contaminate our surroundings and are a cause to many deadly diseases.

\section{Conclusion:}

Although such an approach requires time and persistent dedication, as there is a need to engage with a wider audience and help them reflect repeatedly on social and gender norms which have been followed without much questioning and challenge for generations but with constant efforts from people, Government and Scientists, the day won't be far when malnourishment will be completely elucidated from our nation and the bright minds will bring forth brighter future of our country.

\section{References:}

[1] https://reliefweb.int/report/pakistan/pakistanmalnutrition-serious-threat-among-children-over650000-assisted ; 29/1/2019 at 9:30 AM.

[2] https://www.sciencedaily.com/terms/malnutrition.ht $\mathrm{m} ; 14 / 1 / 2019$ at 8:48 PM.

[3] https://www.nutraingredientsasia.com/Article/2018/01/23/Malnutrition-in-IndiaReport-reveals-a-financial-as-well-as-humanitariancrisis ; $14 / 1 / 2019$ at 11:37 PM.

[4] World Health Organization. Community- Based Management of Severe Acute Malnutrition: A Joint Statement by the World Health Organization, the World Food Programme, the United Nations System Standing Committee on Nutrition and the United Nations Children's Fund. Geneva: World Health Organization, 2007.

[5] https://gh.bmj.com/content/3/2/e000702; $15 / 1 / 2019$ at $11: 36 \mathrm{AM}$.

[6] https://www.researchgate.net/publication/32190460 8_OPEN_DEFECATION_AND_THE_HEALTH_PROBLEMS _IN_INDIA ; $15 / 1 / 2019$ at 12:09 PM.

[7] https://www.islamreligion.com/articles/1892/healthin-islam-part-3/ ;26/1/2019 at 10:36 AM.

[8] This write up has been checked for plagiarism on 29/1/2019 at 3:08 PM through https://smallseotools.com/plagiarism-checker/; showing $97 \%$ unique results and 3\% plagiarism. the report link is; https://smallseotools.com/viewreport/b7dd08f88ca4129047617c41aeb44fde 